of climate science, including atmospheric monitoring of the Southern Hemisphere and understanding the causes of sea-level rise, the nation remains heavily reliant on coal for jobs and electricity. It mines more than half a billion tonnes of the stuff each year, and sells almost threequarters of that abroad. The rest is burnt in Australian power stations, with electricity generation accounting for around one-third of the nation's greenhouse-gas emissions.

It's no coincidence that when Turnbull's political colleague (and then-treasurer) Scott Morrison wanted to criticize environmentalists last year, he brought a lump of coal to parliament and spoke about it in glowing terms. Last week - after Turnbull confirmed he was quitting politics - his son complained about the "undue level of influence" of the coal lobby. Morrison, who replaced Turnbull as prime minister, has yet to announce the fate of the disputed policy, the National Energy Guarantee, which would force emissions generators to show they are meeting annual standards. He has at least said that the country will not withdraw from the Paris climate agreement, a move being pushed by some government members.

He should stand firm. Although the Paris agreement is weak compared with the scale of what is needed, it represents a political triumph and one that places so few binding demands on nations that any withdrawal would be little more than crowd-pleasing theatrics. And most of the crowd won't be pleased: a June poll showed that $59 \%$ of Australians saw climate change as a pressing threat and one that needed action - the highest percentage in a decade.

A larger-scale survey last year of 38 countries showed a similar level of concern. But politicians in many of these places, even those fully behind the need for action on emissions, are also finding it difficult to follow through on pledges. Take Canada, where Justin Trudeau's government last month announced it was scaling back plans for a carbon tax. Last week, Nicolas Hulot, the French environment minister, resigned, claiming that governments around the world are not taking

sufficient steps to tackle green issues such as climate change. And the reckless stance of US President Donald Trump continues to erode climate regulations and embolden climate sceptics. New Zealand, for one, still has ambitions for emissions-reducing laws, but many of the other promises the country made in Paris - including actual cuts to carbon emissions and boosts in foreign aid to help poorer countries adapt - are weakening under political pressure.

Many of those poorer countries are on the front line and will suffer heavily as the weather worsens. So will Australia. Droughts there are

"Australia is likely to face an increase in climate refugees." projected to increase in length and severity as a result of climate change. Heatwaves, floods and bush fires are also linked to global warming, and are predicted to become more common and more extreme. The country's island neighbours in the Pacific are likely to be inundated as sea levels rise. As a result, Australia, whose draconian refugee policy is a source of shame to many citizens, is likely to face an increase in climate refugees.

That these topics are now routinely debated amid mounting public concern about global warming is a victory of sorts for scientists, who must continue their efforts to make the case for action, and to research and speak out about the consequences. And although the current political drama in Australia paints a depressing picture, there is a glimmer of hope. A decade after the financial crash wrested away attention and momentum, climate change is once again at the top of the political agenda.

Things can change quickly in politics, and Australia has a chance to force that change. Already the opposition Labor party has promised a new emissions-reduction scheme. And next year, the country will again vote on its leader. For whoever wins that election, curbing climate change should be at the top of their to-do list - and they must be given the chance to hang around long enough to do so.

\section{What is Life?}

\section{The lectures of physicist Erwin Schrödinger helped to change attitudes in biology.}

I n the winter of 1943, the physicist Erwin Schrödinger invited the Dublin public to hear him deliver a series of lectures he described as "difficult" and that "could not be termed popular". Some 400 people were undeterred and were among the first to hear Schrödinger offer his views on how physics could shed light on the puzzling ability of living organisms to maintain molecular order and organization in the face of what seemed to be the randomizing forces of nature.

Seventy-five years on, some of his ideas remain difficult - controversial even. But they are popular, and are once again drawing people to the Irish capital. Trinity College Dublin will this week host 'Schrödinger at 75 - The Future of Biology', at which a stellar cast of speakers will consider the future of disciplines ranging from ageing and plant science to infectious disease and consciousness.

Schrödinger's lectures were collected into what he called his "little book", What Is Life?, published in 1944 (see Nature 560, 548-550; 2018). Some consider it one of the most influential scientific books of the twentieth century.

The book attracted scientists from other fields to the study of genetics and the molecular mechanisms of life, among them physicist Francis Crick and zoologist James Watson. But can the ideas in this slim volume really supply sufficient motivation for such a diverse programme?

Critics have rightly argued that the book was neither particularly original nor up to date. Schrödinger made the auspicious proposal that the genetic material is an "aperiodic crystal": a structure with a specific but not periodic arrangement of atoms, encoding information that somehow guides the development of the organism. That vision resonated with Crick and Watson as they contemplated the structure of DNA, but it wasn't wholly original. As to how the genetic machinery works, Schrödinger could only point out that it seems to suspend the second law of thermodynamics.

The impact of What Is Life? lies more in its spirit than its substance. Schrödinger presented the problem of life as a puzzle posed to no single discipline. And his timing was perfect: biology was already changing to a mechanistic and microscopic science. This cross-disciplinary relevance applies equally to the topics addressed at the Dublin meeting. The physical-sciences content of artificial intelligence and complex systems is obvious, but understanding of (say) cognitive neuroscience, learning and memory and infectious disease can also benefit from wide-ranging expertise: for example, from the study of network topologies, the thermodynamics of information, and ergodicity (how widely a dynamic system explores its available states).

Happily, chemistry is welcomed to this table too. That subject, after all, is what biologists relied on mid-century to probe and better understand DNA, enzymes and cell signalling. The subsequent emergence of molecular biology, due in large part to some of those inspired by What Is Life?, means that whether Nobel prizes get assigned to 'chemistry' or 'physiology or medicine' is now as arbitrary as whether Nobels in nuclear science in the early twentieth century were awarded in chemistry or physics.

What Is Life? made the case that profound questions about the natural world aren't owned by any academic discipline. Indeed, the Dublin meeting could have gone further by embracing Schrödinger's epilogue on determinism and free will, which invoked philosopher Immanuel Kant and Hinduism (and spoilt the book's chances of publication in devoutly Catholic Ireland). Some eyebrows were raised at this material, but Schrödinger's friend Albert Einstein would have seen nothing amiss in it. Philosophers, ethicists, poets and theologians also have a stake in the future of life. Perhaps they will be invited to the centenary. 
CORRECTION

The Editorial 'What is Life?' (Nature 561, 6;

2018) misnamed Trinity College Dublin. 